\title{
An Exploratory Viewpoint on the Perspectives and Practices of Testing Alternative Option Pricing Models
}

\author{
Gita Madhuri, Mahima Mishra
}

\begin{abstract}
This study examines the perspectives and practices of testing option pricing models, spanning over four decades of literature across prominent journals. The study reveals that the bulk of research on option pricing focuses on developing new models, than comparing relative performance of already existing models. The review has been classified as perspectives and practices in Deterministic and Stochastic Option pricing models to identify the most frequently compared Option pricing models. The review has been presented in a structured order consolidating different perspectives of testing pricing performance of Option pricing models with an objective to gain insights into the existing literature and form a base for developing future research.
\end{abstract}

Keywords: Option pricing models, empirical performance of option pricing models, deterministic option pricing models, stochastic option pricing models

\section{INTRODUCTION}

Estimation of expected volatility of asset prices plays a central role in finance theory. Consequently, accurately estimating this parameter is crucial to meaningful financial decision making. Options trading has become important to the industry as they can be used to hedge risk and the limited loss feature makes them more attractive than the underlying asset. Therefore predicting the price of options \&forecasting their hedging performance has become very crucial not for the growth of financial body of knowledge but also for the investors, hedgers, arbitrageurs. The central issue of Finance has always been Valuation of assets. Role of Expected future volatility cannot be undermined. Consequently, accurately estimating this parameter is crucial to meaningful decision making (B Dumas, 1998).Modigliani and Miller, have promoted the thought that in absence of market imperfections, the aggregate value of claims against the returns of a firm, should be independent of the types of claims issued (John C Cox, 1976).Option Pricing Theory has taken a revolutionary, metamorphic change after the illustrious paper of Black and Scholes in the year 1973.They have derived an option pricing model depending only on observable variables. Subsequent to Black \& Scholes Option pricing Formula many more models came into existence.

Revised Manuscript Received on July 25, 2019

Gita Madhuri,

Research Scholar, Symbiosis Institute of Business Management Dr. Mahima Mishra,

Associate Professor, Symbiosis Institute of Business Management Symbiosis International University, Pune
Though the mathematical tool employed by them was advanced and has obscured the underlying economics, a suggestion by William Sharpe, it is possible to obtain the same results by elementary mathematics (J C Cox, 1979) Option pricing theory can be related to any aspect of problems in the area of Finance, in simple terms all corporate securities can be treated as portfolios of puts and calls on the assets of firm( (J C Cox, 1979). This objectives of this study addresses are the following:

a. To identify the models that have been frequently used to compare the pricing performance of different option pricing models.

b. To identify the different tests that are used to analyze the pricing performance of different models.

c. To identify the scope for future research.

The comprehensive review done for the study is indicated in Table 1 highlights the most frequently compared and tested option pricing models. The Papers mentioned in Table 2 are indicative and are given for ready reference.

Table 1

Review Matrix for most frequently researched and compared Option pricing models in the four decades

\begin{tabular}{|l|l|}
\hline Category & Models Compared \\
\hline Deterministic Models & BS , CEV, Binomial, DVF \\
\hline Stochastic Models & $\begin{array}{l}\text { Hull-White, GARCH, } \\
\text { Heston, Heston-Nandi }\end{array}$ \\
\hline
\end{tabular}

BS: Black \&Scholes Model, CEV: Constant Elasticity of Variance Model, DVF: Deterministic Volatility Function Model, GARCH - Generalized Auto Regressive Conditional Heteroscedasticity Model.

Table 2

Review Matrix for different methodologies adopted to compare alternative option pricing models

\begin{tabular}{|l|l|}
\hline Methodology adopted & Indicative papers \\
\hline In-Sample Performance & (B Dumas, 1998) (Gurudip \\
& Bakshi, 1997) (Kim, 2004) \\
& (Su, 1998) (Singh, 2013) \\
\hline Out-of-Sample Performance & (Gurudip Bakshi, 1997) \\
& (Kim, 2004) (Pachori, \\
& 2013) \\
\hline Hedging Performance & (Gurudip Bakshi, 1997) \\
& (Kim, 2004) \\
\hline
\end{tabular}

This paper is organized in the following manner: Section 2 relates the perspectives of the 
methodologies followed to test performance of Option Pricing Models, Section 3 describes the insights revealed from reviewing the practices followed by researchers over the 4 decades to compare the pricing performance of option pricing models. Section 4 discusses the conclusions derived from the consolidated literature review as well as defines the scope for future research.

\section{PERSPECTIVES OF TESTING PERFORMANCE OF OPTION PRICING MODELS}

Studies in Option theory can be traced to the Journal article titled "The pricing of Options and Corporate Liabilities" by Fischer Black \& Myron Scholes in the year 1973.In this paper Black \& Scholes have derived a theoretical valuation formula for options. Black\& Scholes have compared Options with corporate liabilities, and the analysis \&formula for valuing options can also be used for valuing corporate liabilities such as common stock, corporate bonds and warrants (Fischer Black\& Myron Scholes, 1973)

The hurdles faced by researchers to test the alternative option pricing models are

a. Which source of information to be employed in estimating the model i.e. the option prices, underlying asset prices, option returns, or/and underlying asset returns?

b. Should the recalibration of the model happen by daily data or imposing constant parameters over the full data interval?

c. What diagnostics to be used to do the comparative study?

In answer to the first hurdle, majority of the research studies have exploited the option prices and emphasized on cross sectional properties of option prices for inferring parameters. Simultaneous observations of option prices were also used, when there were noticeable errors in the option data. An implicit "parameter estimation" which identifies key parameters of the risk neutral distribution, was also concluded from an appropriate cross section of option data. Few studies have also combined cross sectional data with asset and/or option returns when estimating the parameters (Bates, Jumps and stochastic volatility : Exchange Rate Processess implicit in Deutchemark Options, 1996a). The statistical techniques of parameter inference along with time series estimation are used.

Early option studies, in answer to the second hurdle used daily parameter recalibration, more as a form of describing data. The rationale behind was that, daily recalibration of parameters was an approximation for a more consistent model with stochastic latent variables, the assumption being that the option prices are not sensitive to neglected randomness. Studies in late 1990's have advanced to the point that recalibration was no longer necessary, since to study pricing it can be confined to resetting key state variables and as the underlying state variables are assumed stationary, so are all data i.e. asset returns, option/asset price ratios, and option returns.

The third hurdle in testing alternative option pricing models was which tests to be chosen to explain the inferences of the studies. Since all tests are in principle informative (Bates, Empirical Option Pricing : a retrospection, 2003); the choice of the researcher for using tests was based on his intention of the issue which he wanted to examine. The fundamental research question in most of the studies was whether the cross sectional option prices are consistent with the time series properties of the underlying asset returns. As the joint evolution of options and asset returns is fundamental to hedging issues, and also assessments of volatility and jump risk premium.

Testing of alternative models has substantially focused on stock index options and the Volatility smirk/smile evidence of negatively skewed risk neutral distributions. Though majority of this work has been done in developed countries and very scanty work in Indian sub-continent has been carried so far. A great deal of learning has happened in the cross sectional option pricing implications of few alternative models and certain amount of understanding has developed about models' qualitative strengths and weaknesses (Bates, 2003).There is an increased emphasis on understanding the quantitative consistency of cross sectional option pricing patterns and time series properties of the underlying asset and of option prices. Research works have been done to understand the empirical inefficiencies of Black and Scholes Model, though the results from these tests point out the deficiencies of the model, yet are very informative and aid in further research in option pricing models.

\section{$2.1 \quad$ Literature Search}

The review of literature was driven by the need to understand the various estimation practices and methodologies used by researchers to compare the ability of different models to capture the pricing performance of options traded in in the markets. In this process of identification of papers which concisely represent this area of study were examined from databases which included- full text articles within EBSCO Host, Elsevier-Science Direct, Emerald Insight and J-Stor. The search was initiated with keywords related to pricing performance of option pricing models published over the years. The preliminary search resulted in 188 articles. Few articles were also identified using cross-referencing from the papers already selected. Reading through the abstracts of these selected articles led to further exclusion of certain articles. The excluded articles were discussing more on the mathematical, computational rationality of the models rather than on the comparative pricing performance of the models in relation to the market outcomes of the options traded. Around 98 articles were eliminated in this preliminary round of analysis of the articles. After the preliminary elimination, few more articles were excluded which were not in accord with the discussion on pricing performance of alternate option pricing models. This entire process has finally come to a closure with 44 articles as a final count across 26 Journals.

\section{PRACTICES IN TESTING ALTERNATIVE OPTION PRICING MODELS}

The publication of Black and Scholes Option pricing model in 1973 has led to the flooding of work in the area of option pricing, which was very less until then. Though the advances in time series econometrics has led to the 
development of numerically intensive techniques commonly employed in derivatives research, but the work in the area of testing alternative option pricing models has been relatively narrow (Bates, 2003).

\subsection{Insights into Testing Deterministic Models}

Earlier studies and option Pricing Models were constructed assuming Volatility to be constant. And all these models with constant volatility parameter were grouped as Deterministic Models.

Testing of alternative models has substantially focused on stock index options and the Volatility smirk/smile evidence of negatively skewed risk neutral distributions. Though majority of this work has been done in developed countries and very scanty work in Indian sub-continent has been carried so far. A great deal of learning has happened in the cross sectional option pricing implications of few alternative models and certain amount of understanding has developed about models' qualitative strengths and weaknesses (Bates, 2003).There is an increased emphasis on understanding the quantitative consistency of cross sectional option pricing patterns and time series properties of the underlying asset and of option prices. Research works have been done to understand the empirical inefficiencies of Black and Scholes Model, though the results from these tests point out the deficiencies of the model, yet are very informative and aid in further research in option pricing models.

According to Fischer Black, there are good reasons for increasing popularity of options in 1970's,such as the fact that brokerage charge for taking a position in options can sometimes be lower than the charge for taking an equivalent position directly in the underlying stock (Black, 1975)

Few years of the origination of Black and Scholes Model (1973), many alternatives to this model started mushrooming and continued in the 1980's with the stochastic volatility models, and testing these alternative models was handicapped in the initial years, as the options data was not readily available until the advent of centralized exchanges. Compared to Black and Scholes model the alternative models were more complicated and were a programming challenge and stochastic volatility increased the dilemma to price those.

The post Black \& Scholes period has seen many new techniques for option valuation and few of them were repeatedly used and citied. Cox and Ross model used jump and diffusion processes to find option valuation formula and solve certain unresolved problems involving potential bankruptcy and payouts (John C Cox, 1976). Need for Testing of Alternative Option Pricing models was recognized with the advent of many option pricing models. Non-Parametric studies were conducted on option data to study the performance of Option pricing model related to the market (J C Cox, 1979).

The 1990's have seen greater facilitation for studying the empirical performance of alternative option pricing models (Bates, 2003).ARCH (Autoregressive Conditional Heteroskedastic) process introduced by Engle (1982) has facilitated modelling several economic phenomena, which were, otherwise almost impossible to comprehend. Research in this area of autocorrelation and stationarity conditions and maximum likelihood estimation has paved way for Testing alternative option pricing models (Bollerslev, 1986). The European call(put)option prices $\mathrm{c}\left(S_{t}, Y_{t}, T ; \theta, \phi\right)$ with maturity $\mathrm{T}$ was computed upon the observed underlying asset price $\square_{\square}$,relevant underlying state variables $\square_{\square}$, and various model parameters $\square$, risk premium $\square$ that determined the risk neutral probability measure. Fourier invasion and other methods were used to calculate implied objective transition densities.

"Quadratic approximation" was used to derive a model that could be accurate, and inexpensive method for pricing American call option and puts (E.Whaley, 1987). Numerical solutions were produced in cases were volatility is correlated with the stock price with support of alternative option pricing models (White, 1987).Few researchers also worked on testing American Option pricing models using jump diffusion process (Courtadon, 1987), simulating arbitrage trade, uncertain volatility, indivisibilities and rebalancing at discrete intervals to test alternative models (Figlewski, 1989).

\subsection{Insights into Testing Stochastic Option pricing models}

Further, 1990's have seen research works on testing whether the observed time series properties of assets and option prices are consistent with the predicted properties. Researchers started constructing models considering Volatility of the Underlying asset to be random, and all such models were grouped as Stochastic Option Pricing models.

The stochastic volatility and Jumps have become the major explanations for option prices being negatively skewed post market crash in 1987 (David.S.Bates, 1998).Hence, stochastic volatility models were more popularly used to better predict option prices as against Black \& Scholes model. Models following a diffusion process with stochastically varying volatility parameter(Stein, 1991)came into existence. Parallel works on stochastic interest rate has stimulated similar work in option pricing models. The model of Heath, Jarrow and Morton(1992) had further work done on generalizing the approach by imbedding stochastic interest rate economy into one containing an arbitrary number of additional risky assets (A.Jarrow, 1992).

Generalized Method of Moments was used to estimate and compare variety of continuous time models of the short term riskless interest rate (K.C. Chan, 1992). These works in stochastic Interest rate models have a considerable influence on the development of work in testing option pricing models. Steven L. Heston derived a closed form solution for stochastic interest rates and that also can be applied to value option prices (Heston, 1993).

Works of Roma and Clifford bring out empirical evidences that asset price volatility is stochastic and hence pricing of options becomes an important problem. They used power series methods to examine alternative methods for pricing options (Roma, 1994).

Review of literature of 1990's also indicates that, dynamic behavior of market volatility was tested and the hypothesis that volatility changes are unpredictable has been rejected by forecasting the volatility implied in the transaction prices of index options (E.Whaley C. R., 1992). The contribution of Derman and Kani lead to an extension of Black \& Scholes model in order to accommodate the structure of market implied volatilities for index options (kani, 1994) and also used volatility smile to construct an implied tree, that can further be used to correctly value all standard calls and puts (Kani, 1994b).

Non parametric approach was used to estimate option prices conditional on 
dividends and volatility. And concluded that dividends alone do not account for all aspects of option pricing and inclusion of stochastic volatility cannot be avoided (Mark Broodie, 1996). Further to this development, we notice deterministic models research has reduced and stochastic models for option pricing have come into existence.

Few constraints that plagued the development of research in testing alternative option pricing models, as noted by Bakshi et.al.(2000),included instantaneous option pricing evolution that cannot be fully captured by underlying asset price movements. Adding to this, these models imply conditional distributions that depend on the level of underlying asset price, which in turn implies non stationary objective and risk neutral conditional distributions for stock, stock index etc (Bates, 2003). And the models use time dependent instantaneous volatilities which that create difficulty for jump models have primarily been used for performing empirical tests.

Standard Jump models have primarily been used to match volatility smiles/smirks and this method has fairly presented for a single maturity and less well for multiple maturities (Bates, 2003).Having jump component has addressed moneyness biases.

The research in testing alternative option pricing models has in fact proven difficult by many studies, as it is almost impossible for any model to match in-sample both cross sectional option prices and the joint distribution of asset and option returns (Bates, Empirical Option Pricing : a retrospection, 2003).

Bakshi, Cao \& Chen derived an option pricing model that allows volatility, interest rates and jumps to be stochastic and then examined several models to compare and evaluate whether generalizations have an improvement in either pricing options accurately or hedging predicting performance of options (Gurudip Bakshi, 1997).

Few researchers in the late 1990's started evaluating the performance of stochastic models as against the Nobel formula of Black Scholes. Corrado and Su have examined the performance of Hull \& White model relative to the pricing \& forecasting performance off Black \& Scholes model (Su, 1998).

Finance researchers have always relied on past behavior of asset prices to predict the future volatility of asset returns. The alternative approach to this thinking was also explored by few researchers.Their argument states that, if option value depends critically on expected future volatility, the volatility expectation of stock market participants can be predicted by inverting the option valuation formulas.

Dumas, Fleming and Whaley evaluated the hedging and price predicting performance of options assuming a deterministic volatility function, option valuation model and compared its performance to Black \&Scholes model to add more empirical understanding to option literature (B Dumas, 1998).

As we move on to 2000's we see more work in stochastic models similar to 1990 's period and research was more concentrated on comparative performance of stochastic and deterministic models. Though mushrooming of many models happened in the 1990's, Black \& Scholes option pricing model was still the favorite of market makers and investors in the option market. The simplicity of the model and observability of variables of Black \& Scholes model, from market makes it easy to calculate and all other models seem to be complex in their calculation.
Since 1990's till date, Black \& Scholes model is still followed in most of the bourses all over the world to calculate option prices on inception when the option is floated across the bourses for trading.

Brandt \& Wu studied the cross sectional performance of different option pricing models in which the volatility of the underlying asset is the deterministic function of the stock price and time.

Christofferson \& Jacobs illustrated the importance of Loss function while comparing models and also their modified Black \& Scholes model, which is a development over Dumas, Fleming and Whaley's Deterministic Volatility function model(DVF) called as Practitioner's Black \& Scholes model has shown better performance than the existing models (Jacobs, 2004).

Review of Literature on research of option pricing models in 2000's shows works done in emerging markets like India, Korea, and Russia etc. Joon Kim and Sol Kim (2003) have tested alternative option pricing models on similar lines like Bakshi, Cao \& Chen, using the sample of Korean Index options and tested the pricing and hedging performance of stochastic volatility models relative to Black \& Scholes model (Kim, 2004). Few works are observed from emerging option markets.

Vipul \& Ahmad tested the forecasting performance of Constant elasticity of variance model relative to Black \& Scholes model (N.Ahmad, 2011). Vipul, Ahmad \& Pachori investigated the comparative out of sample performance of Heston and Nandi model with Black \& Scholes Model (Vipul Kumar Singh, 2011).

Vipul \& Pushkar Pachori have tested a host of stochastic option pricing models to investigate their forecasting performance during turbulent times of the market (Pachori, 2013) and they have also tested a host of Deterministic models to investigate the forecasting performance (Singh, 2013).

\section{CONCLUSION}

This paper has surveyed development of option pricing literature over the years highlighting the hurdles and challenges that researchers have come across, while trying to do a comparative study of option pricing models. The comprehensive survey certainly provides enough evidence that, the popularly followed Black \& Scholes model, has proven anomalies and modifications of the model have come into existence but the current body of knowledge has been unable to establish an acceptable, simpler, universal model other than Black \& Scholes model. It is important to understand and conclude from the review of literature that most of the researchers surveyed $\&$ discussed the models in the context of developed markets and scanty numbers of works have offered evidences from emerging financial markets. Hence, it leaves a huge scope for further research to study the forecasting performance of Option pricing models in emerging markets like India, Indonesia, Russia, Brazil etc.

It is also interesting to note that, though new models, that are modifications to Black \& Scholes or models based on different variables have come into existence but the research so far appears to have laid focus on deriving new models, thus leaving scope for further research to test \& compare the pricing performance of these 
models relative to the market prices. In conclusion it can also be highlighted from our review that the development of models progressed in a logical order starting with Black \& Scholes model. Deterministic model, which considered volatility of underlying asset to be constant addressed the shortcomings of previous model in form of underlying asset distribution, term structure of interest rates or diffusion process or jump processes. And the stochastic models that considered volatility of underlying asset to be random addressed the shortcomings of deterministic models. However while reviewing literature of testing alternative option pricing models it can be noticed clearly that in many markets the performance of Black \& Scholes model outperforms many new models, though there are many anomalies in the Black \& Scholes Model. In instances where the Black \& Scholes model was inferior to any other model, the superiority of that model had to trade off accurate pricing performance at the expense of complexity of the formula/model.

\section{REFERENCES}

[1]. A.Jarrow, K. I. (1992). Pricing options on risky assets in stochastic ineterest economy. Mathematical Finance.

[2]. Ait-Sahalia, Y. a. (1996). Nonparametric Estimation of stateprice densities implicit in financial asset prices. Working Paper, University of Chicago and MIT.

[3]. B Dumas, J. F. (1998). Implied Volatitlity Functions: Empirical tests. Journal of Finance, vol.63, 2059- 2106.

[4]. Bates, D. (1996a). Jumps and stochastic volatility : Exchange Rate Processess implicit in Deutchemark Options. Review in financial studies, 69-108.

[5]. Bates, D. (2003). Empirical Option Pricing : a retrospection. Journal of Econometrics, 387- 404.

[6]. Black, F. (1975). Fact and Fantasy in the use of Options. Financial Analysts Journal.

[7]. Bollerslev, T. (1986). Generalized Autoregressive Conditional heteroskedasticity. Journal of Econometrics.

[8]. Brooks, D. M. (2015). An introduction to Derivatives and Risk Management. Cengage.

[9]. Courtadon, J. N. (1987). Tests of an American Option Pricing Model on the Foreign currency options market. Journal of Financial and quantitative Analysis.

[10].D Backus, S Foresi \& L Wu. (1997). Accounting for biases in Black and Scholes. CRIF working Paper series. New York University.

[11].David.S.Bates. (1998). Post-'87 Crash Fears in the S\&P 500 Futures Option Market. Journal of Econometrics.

[12].E.Whaley, C. R. (1992). Market volatility prediction and the efficiency of the S\&P 100 index option market. Journal of Financial Economics.

[13].E.Whaley, G. B.-A. (1987). Efficient Analytic Approximation of American Option Values. The Journal of Finance.

[14].Figlewski, S. (1989). Options arbitrage in Imperfect markets. The Journal of Finance.

[15].Fischer Black\& Myron Scholes. (1973). The Pricing of Options and Corporate Liabilities. Journal of Political Economy, vol 81,637-659.

[16].Galai, D. (1983). The componenets of Return from Hedging

[17]. Gurudip Bakshi, C. C. (1997). Empirical performance of Option pricing models. journal of finance, Vol.52,2003-2049.

[18].Heston, S. L. (1993). A Closed form Solution for Options with Stochastic Volatility with applications to Bond and Currency options against stocks. Journal of Business.

Options. The Review of Financial studies, Vol 6 No 2, 327343.

[19].Hull, J. C. (2009). Options, Futures and other derivatives. Pearson.

[20]. J C Cox, S. A. (1979). Option pricing : A Simplified Approach. Journal of Financial economics.

[21].Jacobs, P. C. (2004). The Importance of Loss Function in Option Pricing. Journal of Financial Economics, Vol.72, No 2, 291-318.

[22].John C Cox, S. A. (1976). The Valuation of Options for alternative Stochastic Processes. Journal of Financial Economics.

[23]. K.C. Chan, G. K. (1992). An Empirical Comparision of Alternative Models of teh Short term Interest rate. The Journal of Finance.

[24].kani, E. d. (1994). The Volatility Smile and Its Implied Tree. Quantitative Strategies .

[25]. Kani, E. D. (1994b). Riding on Smile. Risk, 7(2) , 32-39.

[26].Kim, S. K. (2004). Empirical Comparision ofAlternative Stochastic Models: Evidence from Korean KOSPI 200 Index option market. Pacific Basin Financial Journal, 117-142.

[27]. Mark Broodie, J. D. (1996). American Options with Stochastic Dividends and Volatility : A Non parametric Investigation. CIRANO.

[28]. McDonald, R. L. (2013). Derivatives Markets. Kellogg School of Management: Pearson.

[29]. McDonald, R. L. (June, 2012). Derivatives Markets. Pearson.

[30].N.Ahmad, V. K. (2011). Forecasting performance of Constant Elasticity of Variance model:Empirical Evidence from India The International Journal of applied Economics and Finance.

[31].Pachori, V. K. (2013). A Kaleidoscopic Study of Pricing performance of STochastic Volatility Option pricing Models : Evidence from Recent Indian Economic Turbulence. Vikalpa.

[32]. Roma, C. A. (1994). Stochastic Volatility Option pricing. Journal of Financial and Quantitative Analysis.

[33]. S L Heston, S. N. (2000). A closed form GARCH option valuation model . Review of Financial studies, Vol 13, No.3 585-625.

[34]. Singh, P. P. (2013). Empirical competitiveness of deterministic option pricing models : Evidences from the recent waves of Financial upheavals in India. Journal of Derivatives \& Hedge Funds.

[35].Stein, E. S. (1991). Stock price distribution with stochastic volatility :An Analytical Approch. Review of Financial studies, vol. 4 727-752.

[36].Su, C. C. (1998). An empirical test of Hull -White option pricing model. Journal of Future Markets, 18(4), 363-378.

[37]. Vipul Kumar Singh, N. A. (2011). Empirical Analysis of GARCH and Practitioner Black Scholes Model for pricing S\&P CNX Nifty 50 index options of India. Decision.

[38]. White, J. C. (1987). The Pricing of Options with Stochastic Volatilities. Journal of Finance, Vol 42, 281-300.

Published By:

Blue Eyes Intelligence Engineering 